\title{
PREVALÊNCIA DE RISCO PARA SÍNDROME DE BURNOUT EM POLICIAIS MILITARES
}

\author{
Rosana Amora Ascari ${ }^{1}$, Mellani Dumke ${ }^{2}$, Paola Maritssa Dacol ${ }^{3}$, Sérgio Maus Junior ${ }^{4}$, Clodoaldo Antônio De \\ $\mathrm{Sá}^{5}$, Liana Lautert ${ }^{6}$
}

RESUMO: Trata-se de um estudo transversal e descritivo de abordagem quantitativa, com 127 policiais militares lotados num município do oeste catarinense. O estudo visou a avaliar o risco de desenvolvimento da Síndrome de Burnout em policiais militares, por meio do Maslach Burnout Inventory - Human Services Survey. Os dados foram coletados nos meses de outubro a dezembro de 2014. Houve predomínio do sexo masculino, entre 18 e 39 anos de idade, com companheiro, graduado, sem filhos, que não trabalha em outro lugar fora da corporação e atua em escala de plantão. Nenhum indivíduo foi identificado com a Síndrome de Burnout, não estavam com nível baixo de Realização Profissional, associado níveis elevados de Exaustão Emocional e Despersonalização. O estudo evidenciou que não há incidência da Síndrome entre os policiais, contudo, aponta que se encontram em prevalência de risco para seu desenvolvimento.

DESCRITORES: Estresse; Esgotamento profissional; Burnout; Saúde do trabalhador; Polícia.

\section{PREVALENCE OF RISK FOR BURNOUT SYNDROME AMONG MILITARY POLICE}

\begin{abstract}
This is a transversal and descriptive study with a quantitative approach, with 127 military police officers assigned to a municipality in the west of the Brazilian state of Santa Catarina. The study aimed to assess the risk of developing Burnout Syndrome among military police officers, through the use of the MaslachBurnout Inventory-Human Services Survey. The data were collected in October - December 2014. There was a prevalence of men, aged between 18 and 39 years old, with a partner, educated to degree level, without children, who did not work anywhere else,and who worked on a shift system. No individual was identified as having Burnout Syndrome and they did not have a low level of Professional Fulfillment, associated withhigh levels of Emotional Exhaustion and Depersonalization. The study evidenced that there is no incidence of the Syndrome among the police officers: however, it indicates that there is a prevalence of riskfor its development among them.
\end{abstract}

DESCRIPTORS: Stress; Burnout, professional; Burnout; Occupational health; Police.

\section{PREVALENCIA DE RIESGO PARA SÍNDROME DE BURNOUT EN POLICIALES MILITARES}

RESUMEN: Este es un estudio transversal y descriptivo de abordaje cuantitativo, con 127 policiales militares de un municipio de este Santa Catarina. El objetivo fue evaluar el riesgo de desarrollo del Síndrome de Burnout en policiales militares, por medio de Maslach Burnout Inventory-Human Services Survey. Los datos fueron obtenidos en los meses de octubre a diciembre de 2014. Fue predominante el sexo masculino, edad entre 18 y 39 años, con compañero, graduado, sin hijos, que no trabaja en otro sitio fuera de la corporación y actua en escala de plantón. Ningún individuo fue identificado con Síndrome de Burnout, no estaban con nivel bajo de Realización Profesional, asociandose niveles elevados de Exaustión Emocional y Despersonalización. El estudio evidenció que no hay incidencia del Síndrome entre los policiales, sin embargo, apunta que se encuentran en prevalencia de riesgo para su desarrollo. DESCRIPTORES: Estrés; Agotamiento profesional; Burnout; Salud del trabajador; Policía.

${ }^{1}$ Enfermeira. Doutoranda em Enfermagem. Docente de Enfermagem da Universidade do Estado de Santa Catarina. Chapecó, SC, Brasil.

${ }^{2}$ Enfermeira. Prefeitura de Chapecó. Chapecó, SC, Brasil.

${ }^{3}$ Enfermeira. Hospital Regional do Oeste - Chapecó. Chapecó, SC, Brasil.

${ }^{4}$ Discente de Enfermagem. Universidade do Estado de Santa Catarina. Chapecó, SC, Brasil.

${ }^{5}$ Educador Físico. Doutor em Ciência do Movimento Humano. Docente da Universidade Comunitária da Região de Chapecó. Chapecó, SC, Brasil.

${ }^{6}$ Enfermeira. Doutora em Psicologia. Docente da Universidade Federal do Rio Grande do Sul. Porto Alegre, RS, Brasil.

Autor Correspondente:

Recebido: 04/01/2016

Rosana Amora Ascari

Finalizado: 08/06/2016

Universidade do Estado de Santa Catarina

R. Sete de Setembro, 99 - 89801-140 - Chapecó, SC, Brasil

E-mail: rosana.ascari@udesc.br 


\section{INTRODUÇÃO}

O trabalho representa uma atividade consciente do indivíduo, fruto do esforço para transformar a natureza em produtos ou serviços ${ }^{(1)}$. Nem sempre a relação entre o trabalho e a saúde/doença constituiu foco de atenção dos estudiosos. Contudo, as constantes mudanças que vêm ocorrendo no mundo, tais como o ritmo acelerado de trabalho, a competitividade e produção capitalista, exigem do indivíduo maior tempo na preparação e qualificação profissional e influenciam fortemente a saúde dos trabalhadores ${ }^{(2)}$.

As doenças originadas no e pelo trabalho às vezes são percebidas já em estágios avançados, uma vez que frequentemente apresentam sinais e sintomas comuns a outras doenças, o que mascara a identificação precoce deste agravo, repercutindo tanto na saúde do trabalhador como gerando custos para a empresa e serviços de saúde. Entre as diversas classes de trabalhadores, os policiais possuem maior risco de morte e propensão ao desenvolvimento de estresse, devido às relações internas próprias da corporação, à sobrecarga de trabalho e ao caráter das atividades que realizam ${ }^{(3)}$.

Estudos $^{(4-8)}$ têm sinalizado consequências do trabalho na saúde de policiais, as quais nos remetem à necessidade de investimentos para conhecer as causas e implementar estratégias para minimizar, ou mesmo eliminar, os agravos à saúde do policial, sobretudo e com isso, contribuindo para a preservação da ordem pública.

A função do policial, como agente da lei e repressor da criminalidade, exige alerta constante e prontidão para atuar em situações inesperadas num contexto de crescente violência urbana. Ele atua, geralmente, em ambientes muitas vezes perigosos e insalubres, acrescido às pressões e exigências do próprio trabalho. Somam-se a isto a rígida hierarquia do serviço militar, além de pressões e demandas administrativas e organizacionais, fatores que podem causar estresse e afetar negativamente a saúde e o estilo de vida desse profissional. Sendo assim, constata-se que os policiais militares enfrentam muitos desafios para promover a ordem e manter a segurança pública. Todo esse quadro favorece o desenvolvimento da Síndrome do Burnout e outras doenças relacionadas ao trabalho ${ }^{(9-10)}$.

Monitorar e aconselhar as atividades nos ambientes laborais com o intuito de promover a saúde, evitando acidentes e contribuindo na reabilitação, são maneiras de se manter a salubridade laboral, e ainda podem resultar em melhora da qualidade de vida de trabalhadores.

Na área de saúde pública, o campo da Saúde do Trabalhador investiga as relações entre o trabalho e a saúde com foco na promoção e proteção da saúde do trabalhador ${ }^{(11)}$. No Brasil, a Política Nacional de Saúde do Trabalhador, no âmbito do Sistema Único de Saúde (SUS), tem a intenção de reduzir os acidentes e doenças relacionados ao trabalho, por meio da promoção, reabilitação e vigilância na área da saúde, tendo como linhas de ação a atenção integral à saúde, a articulação intra e intersetorial, a participação da população, o apoio a estudos e a capacitação de recursos humanos. Dentre as doenças ocupacionais encontradas que é objeto dessa Política, está a Síndrome de Burnout (SB). Conforme o Ministério da Saúde (MS), esse agravo tem maior predominância sobre os profissionais da saúde como: médicos, enfermeiros, assistentes sociais, dentistas e fisioterapeutas, além de outras categorias profissionais como professores, policiais, bombeiros e demais profissões que estão sujeitas ao contato diário com o público, o que exige grande carga emocional ${ }^{(12)}$.

Durante o exercício profissional, os trabalhadores estão expostos a diversos estressores psicossociais, que podem estar relacionados tanto à natureza do trabalho como ao contexto institucional e social onde estas atividades são realizadas. Ao ser realizada uma avaliação dos níveis de estresse geral, esta pode indicar vulnerabilidade do indivíduo à Síndrome de Burnout ${ }^{(13)}$.

É oportuno ressaltar que Burnout é uma síndrome que afeta trabalhadores que estão em contato com pessoas durante suas jornadas de trabalho, causando exaustão emocional e despersonalização. Uma característica desta síndrome é o aumento de sentimentos relacionado a exaustão emocional, aliada ao desenvolvimento de sentimentos e atitudes negativas frente às pessoas que se relaciona no e pelo trabalho. Atitudes que parecem estar ligadas à experiência da exaustão emocional, pela exposição à alta demanda decorrente do trabalho e à falta de recursos emocionais que a pessoa possui para enfrentar tal situação. Esses dois aspectos, Exaustão Emocional e Despersonalização, parecem estar 
interligados. Outra dimensão que constitui o Burnout é a forma de avaliar a si, sobretudo no que diz respeito ao seu trabalho, de maneira negativa, caracterizando a baixa Realização Profissional, uma vez que o indivíduo se sente infeliz e insatisfeito ${ }^{(14)}$.

A definição de estresse ocupacional não é claramente definida na literatura, assim, a avaliação geral do estresse permite que ocorra a indicação das condições gerais de saúde do indivíduo e o risco de desenvolver outras doenças. O estresse e trabalho podem estar associados por meio de outros fatores, tais como o dever no trabalho, o tempo de serviço e setor de atuação, entre outros ${ }^{(15)}$.

A constante exposição a agentes estressores podem levar à Síndrome de Burnout, caracterizada por estresse de caráter persistente relacionado ao trabalho, fruto da constante e repetitiva pressão emocional $^{(14)}$ aliada ao intenso envolvimento com pessoas por longos períodos de tempo ${ }^{(12)}$.

O Maslach Burnout Inventory (MBI) em sua primeira versão foi direcionado aos profissionais da saúde, em seguida foi elaborada uma segunda versão voltada para os trabalhadores da educação e existe hoje uma versão atual, considerada mais generalista, a qual não se foca exclusivamente nos indivíduos que trabalham com pessoas. O MBI que avalia a Síndrome de Burnout se caracteriza por três dimensões: Exaustão Emocional (EE), Despersonalização (DE) e baixa Realização Profissional (RP), o que possibilita verificar a frequência com que o trabalhador concebe a baixa RP, representada por uma reação negativa frente à capacidade de executar o trabalho e interagir com as demais pessoas no trabalho; EE representada pela incapacidade em estabelecer vínculo afetivo e emocional; e a DE, na qual o indivíduo se mostra indiferente a todas as pessoas de contato durante as atividades laborais ${ }^{(16)}$.

Estudo sugere que a EE é a dimensão considerada o traço inicial do Burnout, acompanhada de sintomas físicos e psíquicos e, que a DE sinaliza o aspecto típico da síndrome de Burnout, ou seja, fica visível a falta de sensibilidade e humanização ao realizar o atendimento aos clientes, tratando-os com frieza e indiferença ${ }^{(13)}$.

O trabalhador que sofre da SB tende a procurar o afastamento de suas atividades. Características como o tipo de ocupação, tempo de profissão, tempo na instituição, trabalho por turnos, sobrecarga, relação entre o profissional e o cliente, tipos de clientes, relacionamento entre os colegas de trabalho, insatisfação no trabalho, falta de responsabilidade, ausência de progressão no trabalho, conflito com os valores pessoais e falta de feedback têm forte influência para o desenvolvimento da $\mathrm{SB}^{(17)}$.

A exposição laboral do policial às condições acima referidas, desencadeia tanto o medo individual quanto o medo por sua própria família ${ }^{(18)}$.

Considerando a frequente exposição de policiais militares à violência urbana, ao confronto com vândalos e a convivência com a rígida disciplina e hierarquia militar, o presente estudo teve por objetivo avaliar o risco de desenvolvimento da Síndrome de Burnout em policiais militares, por meio do Maslach Burnout Inventory - Human Services Surveye, bem como conhecer o perfil dos policiais militares vinculados a um Batalhão da Polícia Militar no oeste catarinense, Brasil, por meio de questionário sociolaboral.

\section{METODOLOGIA}

Trata-se de um estudo transversal, exploratório e descritivo de abordagem quantitativa, tendo como cenário um Batalhão da Policia Militar (BMP) no Oeste catarinense. No município foco desta pesquisa estão lotados no BPM 272 policiais que atuam em diferentes áreas, tais como: Serviço interno, Radiopatrulha, Canil, Cavalaria, ROCAM (Rondas Ostensivas com Apoio de Moto), Pelotão de Patrulhamento Tático, Polícia Ambiental, Agência de Inteligência e Programa Educacional de Resistência às Drogas.

Foram convidados a participar do estudo 129 policiais, sendo a seleção destes de forma intencional, a partir de uma lista nominal fornecida pelo Tenente Coronel, optando-se por aqueles policiais que estavam no batalhão no momento da coleta de dados e que manifestaram interesse em participar da pesquisa. Aceitaram participar 127 trabalhadores.

Foram incluídos na pesquisa policiais com pelo menos um ano de atuação no cenário pesquisado, 
que aceitaram participar da pesquisa e assinaram o Termo de Consentimento Livre e Esclarecido. Foram excluídos do estudo os policiais em férias, em licença ou com algum atestado no período da coleta de dados.

Os dados foram coletados no período de outubro a dezembro de 2014. O local de coleta de dados foi a própria instituição em diferentes dias da semana, priorizando-se o horário da troca de plantão, ou seja, 07:00, 13:00 e 18:00 horas. Os instrumentos foram preenchidos pelos participantes individualmente e na presença do pesquisador.

Utilizou-se o Inventário de Burnout - MBI - Maslach Burnout Inventory, traduzido e adaptado(19). O referido instrumento é composto por uma escala tipo likert com pontuação de 1 a 5 e apresenta vinte e dois (22) itens que se encontram agrupados nas três dimensões da SB. A primeira escala, que trata da Exaustão Emocional (EE), é composta por nove (9) itens nas questões $1 ; 2 ; 3 ; 6 ; 8 ; 13 ; 14 ; 16$ e 20; a segunda escala trata da Despersonalização (DE) e é composta por cinco (5) questões: a 5; 10; 11; 15 e 22; e a terceira escala, que aborda a baixa Realização Profissional (RP), é composta por oito (8) questões, a saber: $4 ; 7 ; 9 ; 12 ; 17 ; 18 ; 19$ e 21 . Como pontuação da resposta, adotou-se: 1 para "nunca"; 2 para "raramente"; 3 para "algumas vezes"; 4 para "frequentemente"; e 5 para "sempre" (20). A escala possui três níveis correspondendo ao tipo "nulo ou baixo", quando apresentar-se 0 a 10 pontos, ao tipo "médio" quando encontrar-se de 11 a 20 pontos, e ao tipo "alto" quando apresentar-se de 21 a 48 pontos(20). Considera-se com Síndrome de Burnout os profissionais com as pontuações de EE e DE alta, e baixos valoresem $\mathrm{RP}^{(19)}$. $\mathrm{O}$ instrumento contou também com um questionário para coleta de dados sociolaborais, para elucidação do perfil dos participantes.

Os dados obtidos por meio dos questionários sofreram dupla digitação em programa Excel $^{\circledR}$, sendo as inconsistências corrigidas e os dados importados para o programa SPSS 20.0. - Statistical Package for Social Sciences para análise estatística. Foram realizados os testes: Qui-quadrado de Pearson e Exato de Fisher. Testou-se a associação entre as variáveis: estado civil, possuir ou não filhos, turno de trabalho e possuir ou não outro emprego com as três subescalas do MBI.

O presente estudo foi aprovado pelo Comitê de Ética em Pesquisa com Seres Humanos da Universidade do Estado de Santa Catarina (CEPSH/UDESC), sob o Parecer $n^{\circ} 756.207$ de 14/08/2014 e seguiu a Resolução 466/2012 do Conselho Nacional de Saúde(21).

\section{RESUlTADOS}

Quanto ao perfil dos participantes, houve predomínio de policiais militares do sexo masculino, idade entre 18 a 28 anos e casados $(n=56 ; 44,09 \%)$. A maior parte dos indivíduos possuía curso de graduação $(n=74 ; 58,26 \%)$, não possuíam filhos $(n=66 ; 51,96 \%)$, nem outro emprego $(n=111 ; 87,40 \%)$ e trabalhavam por escalas de plantão $(n=88 ; 69,29 \%)$. O tempo de trabalho na instituição variou entre um e 10 anos, e $81,10 \%(n=103)$ tinham carga de trabalho de 31 a 40 horas semanal, enquanto $55,90 \%(n=71)$ usufruíram de férias nos últimos 10 meses. A maioria dos policiais militares tinha bom relacionamento com os colegas de trabalho $(n=65 ; 51,58 \%), 63$ policiais $(49,60 \%)$ afirmaram sentir pouca segurança em sua vida em relação à profissão, 92,12\% $(n=117)$ praticavam atividade física regularmente, 94,48\% $(n=120)$ não eram tabagistas e 116 (91,33\%) não faziam uso de medicação e não apresentavam dificuldade para dormir ( $\mathrm{n}=112$ participantes).

Apresenta-se, nas Tabelas 1, 2, e 3, a relação das quatro variáveis investigadas neste estudo (estado civil, ter ou não filhos, turno de trabalho e possuir ou não outro emprego) com as três dimensões da Síndrome de Burnout, as quais não apresentaram significância estatística.

O resultado dos cruzamentos das três dimensões da Síndrome de Burnout com as quatro variáveis propostas não evidenciou níveis de associação estaticamente significativa, considerando o valor de p bicaudal menor que 0,05. Nenhum indivíduo estava com nível baixo de RP, considerando que para estar em Burnout é necessário que este nível esteja baixo, associado com os níveis elevados de EE e DE.

Quando analisado o risco para o desenvolvimento da SB e as variáveis propostas, percebeu-se um nível de Exaustão Emocional do tipo alto em 66,92\% dos participantes, o que expressa os sentimentos negativos dos policiais frente ao seu trabalho. A Despersonalização foi caracterizada do tipo médio 
em $67 \%$ indicando que estes profissionais apresentam menor sensibilidade, além disso, 3,13\% apresentaram Despersonalização em nível Alto. Contudo, a Realização Profissional foi do tipo alto (96\%), o que significa que os policiais militares investigados conseguem manter a eficácia e produção no trabalho.

Tabela 1 - Avaliação do nível de Exaustão Emocional (EE) em policiais militares. Chapecó, SC, Brasil, 2014

\begin{tabular}{|c|c|c|c|c|c|c|c|}
\hline \multirow[t]{2}{*}{ Variáveis } & \multicolumn{2}{|c|}{ Nulo ou Baixo } & \multicolumn{2}{|c|}{ Médio } & \multicolumn{2}{|c|}{ Alto } & \multirow[t]{2}{*}{$\mathbf{p}$} \\
\hline & $\mathbf{N}$ & $\%$ & $\mathbf{N}$ & $\%$ & $\mathbf{N}$ & $\%$ & \\
\hline Estado Civil & & & & & & & 0,695 \\
\hline Solteiro & 0 & 0 & 18 & 14,1 & 32 & 25,19 & \\
\hline Casados & 1 & 0,78 & 15 & 11,81 & 39 & 30,7 & \\
\hline Em União Estável & 0 & 0 & 8 & 6,29 & 14 & 11,02 & \\
\hline Filhos & & & & & & & 0,572 \\
\hline Não & 1 & 0,78 & 23 & 18,11 & 42 & 33,07 & \\
\hline Sim & 0 & 0 & 18 & 14,17 & 43 & 33,85 & \\
\hline Turno de Trabalho & & & & & & & 0,271 \\
\hline Em Turnos & 1 & 0,78 & 14 & 11,02 & 24 & 18,89 & \\
\hline Escalas de Plantão & 0 & 0 & 27 & 21,25 & 61 & 48,03 & \\
\hline Outro Emprego & & & & & & & 0,632 \\
\hline Não & 1 & 0,78 & 37 & 29,13 & 73 & 57,48 & \\
\hline Sim & 0 & 0 & 4 & 3,14 & 12 & 9,44 & \\
\hline
\end{tabular}

Tabela 2 - Avaliação do nível de Despersonalização (DE) em policiais militares. Chapecó, SC, Brasil, 2014

\begin{tabular}{|c|c|c|c|c|c|c|c|}
\hline \multirow[t]{2}{*}{ Variáveis } & \multicolumn{2}{|c|}{ Nulo ou Baixo } & \multicolumn{2}{|c|}{ Médio } & \multicolumn{2}{|c|}{ Alto } & \multirow[t]{2}{*}{$\mathbf{P}$} \\
\hline & $\mathbf{N}$ & $\%$ & $\mathbf{N}$ & $\%$ & $\mathbf{N}$ & $\%$ & \\
\hline Estado Civil & & & & & & & 0,874 \\
\hline Solteiro & 16 & 12,59 & 32 & 25,19 & 2 & 1,57 & \\
\hline Casados & 15 & 11,81 & 39 & 30,7 & 1 & 0,78 & \\
\hline Em União Estável & 6 & 4,72 & 15 & 11,81 & 1 & 0,78 & \\
\hline Filhos & & & & & & & 0,521 \\
\hline Não & 17 & 13,38 & 46 & 36,22 & 3 & 2,36 & \\
\hline Sim & 20 & 15,74 & 40 & 31,49 & 1 & 0,78 & \\
\hline Horários de Trabalho & & & & & & & 0,312 \\
\hline Em Turnos & 14 & 11,02 & 25 & 19,68 & 0 & 0 & \\
\hline Escalas de Plantão & 23 & 18,11 & 61 & 48,03 & 4 & 3,14 & \\
\hline Outro Emprego & & & & & & & 0,869 \\
\hline Não & 33 & 25,98 & 74 & 58,26 & 4 & 3,14 & \\
\hline Sim & 4 & 3,14 & 12 & 9,44 & 0 & 0 & \\
\hline
\end{tabular}


Tabela 3 - Avaliação do nível de baixa Realização Profissional (RP) em policiais militares. Chapecó, SC, Brasil, 2014

\begin{tabular}{|c|c|c|c|c|c|c|c|}
\hline \multirow[t]{2}{*}{ Variáveis } & \multicolumn{2}{|c|}{ Nulo ou Baixo } & \multicolumn{2}{|c|}{ Médio } & \multicolumn{2}{|c|}{ Alto } & \multirow[t]{2}{*}{$\mathbf{P}$} \\
\hline & $\mathbf{N}$ & $\%$ & $\mathbf{N}$ & $\%$ & $\mathbf{N}$ & $\%$ & \\
\hline Estado Civil & & & & & & & 0,488 \\
\hline Solteiro & 0 & 0 & 3 & 2,36 & 47 & 37 & \\
\hline Casados & 0 & 0 & 1 & 0,78 & 54 & 42,51 & \\
\hline Em União Estável & 0 & 0 & 1 & 0,78 & 21 & 16,53 & \\
\hline Filhos & & & & & & & 1 \\
\hline Não & 0 & 0 & 3 & 2,36 & 63 & 49,6 & \\
\hline Sim & 0 & 0 & 2 & 1,57 & 59 & 46,45 & \\
\hline Horário de Trabalho & & & & & & & 0,312 \\
\hline Em Turnos & 0 & 0 & 1 & 0,78 & 38 & 29,92 & \\
\hline Escalas de Plantão & 0 & 0 & 4 & 3,14 & 84 & 66,14 & \\
\hline Outro Emprego & & & & & & & 1 \\
\hline Não & 0 & 0 & 5 & 3,93 & 106 & 83,47 & \\
\hline Sim & 0 & 0 & 0 & 0 & 16 & 12,6 & \\
\hline
\end{tabular}

\section{DISCUSSÃO}

Considerando os 127 trabalhadores respondentes do MBI para a escala de Exaustão Emocional, constituída a partir de nove questões, constatou-se um grande número de policiais com alto nível de exaustão emocional, considerado o fator mais importante na análise da Síndrome de Burnout, o que indica que há um processo de Burnout em andamento ${ }^{(22)}$. Essa dimensão quando elevada é acompanhada por sintomas físicos e psíquicos, sendo considerado o processo inicial pra o desenvolvimento da Síndrome de Burnout.

A Despersonalização representa a eliminação da singularidade do "outro" na relação interpessoal. Os resultados deste estudo sinalizam um nível médio de Despersonalização, sendo que já se percebe alguma presença de nível alto, situação considerada crítica, uma vez que os policiais lidam constantemente com pessoas e têm a árdua tarefa de protegê-las para manter a ordem e a segurança pública. Essa despersonalização denota a presença de atitudes negativas do profissional no relacionamento com os usuários dos seus serviços, tais como a insensibilidade, indiferença, falta de preocupação ${ }^{(23)}$.

Quando um indivíduo está sendo muito exigido no trabalho e carente de recursos emocionais para lidar com estas situações, ele reage com frieza e rispidez no contato com seus colegas e clientes, o que se configura nos sintomas característicos da despersonalização(19).

Na análise da baixa Realização Profissional, evidenciou-se que os policiais estão com nível do tipo alto, o que indica que a maioria dos investigados consegue lidar com a realidade do seu trabalho. Do contrário, o profissional estaria pré-disposto a problemas psicossomáticos e ao adoecimento físico decorrentes de motivos psicológicos ${ }^{(3)}$, podendo evoluir para licença e afastamento do trabalho.

Algumas características do trabalhador podem não levar à Síndrome de Burnout, mas podem facilitar ou inibir a ação de agentes estressores. Entre elas pode-se considerar a idade, sexo, nível educacional, estado civil, presença de filhos, tipo de personalidade, falta de motivação e idealismo ${ }^{(17)}$.

Estudo sinalizou que quanto maior a carga horária de trabalho do profissional, mais desgastante será sua atividade laboral ${ }^{(24)}$, o que corrobora com os achados deste estudo que evidenciou que os policiais que atuam em escalas de plantão estão mais expostos ao desenvolvimento da Síndrome de Burnout do que os profissionais que trabalham em turnos definidos.

Outro estudo realizado com 134 médicos anestesiologistas para avaliar a prevalência da síndrome 
do esgotamento profissional identificou níveis significativos de baixa realização profissional $(47,7 \%)$, despersonalização (28,3\%) e exaustão emocional (23,1\%) com prevalência da síndrome de Burnout em $10,4 \%$ dos participantes, acometendo principalmente homens, entre 30 a 50 anos, com mais de dez anos de profissão, com atuação em plantões noturnos e sedentários ${ }^{(25)}$.

Nesta pesquisa os participantes apresentaram um bom relacionamento com os colegas, podendo ser este um fator importante de proteção para não desencadeamento da Síndrome de Burnout. O fato de haver dificuldades de relacionamentos com os colegas no trabalho pode resultar em frustração, cansaço e falta de satisfação, acarretando sofrimento ${ }^{(26)}$.

Ao vivenciar situações estressantes, o indivíduo se utiliza de mecanismos psicológicos para reduzir o impacto desses estressores e garantir a homeostase do organismo. Tal mecanismo é denominado estratégias de coping ou estratégias de enfrentamento. O coping representa um conjunto das estratégias cognitivas e comportamentais utilizadas pelas pessoas para se adaptarem a circunstâncias as quais avaliam como adversas ou estressantes e envolve quatro características principais que são: interação do indivíduo com o ambiente, administração da situação estressora, avaliação da situação, e mobilização de esforços ${ }^{(27)}$.

Contudo, a prática de atividade física, o pleno usufruto das férias e não usar medicações também podem ser considerados fatores de proteção do indivíduo contra o desenvolvimento da Síndrome de Burnout.

O tabagismo é um fator que gera inúmeras doenças, além da dependência, sendo uma das causas de maior mortalidade no mundo. Em policiais militares a prevalência de uso de cigarro é menor que a média encontrada na população brasileira ${ }^{(28)}$. Neste particular, a presente pesquisa mostrou concordância com a literatura, pois somente 7 dentre os 127 policiais investigados eram tabagistas.

Os participantes não apresentaram dificuldade para dormir e nem por trabalhar 12 horas. O fato de possuir ou não outro emprego também não foi relevante, visto que são poucos os que trabalham em outra instituição. Segundo a literatura ${ }^{(29)}$, o que afeta negativamente a qualidade de vida do policial são fatores como ter dois empregos; trabalhar em mais de um turno; permanecer cerca de 12 horas na rua, sem intervalos para refeições; trabalhar sob pressão; permanecer alerta e dormir pouco, levando em consideração que ele é um profissional que exerce atividades desgastantes, causando irritabilidade, insônia e envelhecimento precoce devido ao estresse.

Implementar atividades para prevenção de doenças e promoção da saúde dos trabalhadores é importante para qualquer organização laboral, uma vez que diminui o risco de desenvolvimento da Síndrome de Burnout. O estímulo à prática de atividade física e ao bom relacionamento interpessoal são formas de aumentar a qualidade de vida no trabalho(2). A redução dos problemas existentes no ambiente de trabalho favorecem melhores condições laborais e de vida para os trabalhadores, repercutindo na melhora do atendimento à população ${ }^{(30)}$.

O adoecimento do policial merece um olhar atento da equipe de Saúde do Trabalhador, especialmente do enfermeiro, pela proximidade com o trabalhador durante as diferentes consultas de enfermagem e atividades de promoção da saúde, levando em consideração que o processo saúdetrabalho-adoecimento é complexo e resulta em significativo impacto econômico e social. Desta forma, estratégias voltadas à identificação precoce de situações estressoras e formas de enfrentamento do desgaste no ambiente laboral podem contribuir para minimizar o estresse e, consequentemente, $o$ risco de adoecimento.

Embora o número de participantes deste estudo tenha sido limitado, os resultados evidenciam a necessidade da investigação precoce dos problemas de saúde relacionados ao trabalho e que possam levar ao desenvolvimento da Síndrome de Burnout.

\section{- CONCLUSÃO}

O estudo demonstrou que não há incidência de Síndrome de Burnout entre os policiais militares participantes, contudo, sinaliza que mais de $66 \%$ dos profissionais estão em situação de risco para o desenvolvimento da síndrome de Burnout, uma vez que apresentam Exaustão Emocional em nível 
alto e Despersonalização em nível médio pela classificação do Inventário de Burnout (MBI), apesar de mostrarem uma Realização Profissional alta. O MBI identificou um nível alto de Exaustão Emocional entre os policiais, sinalizando um problema considerando que esta dimensão representa o processo inicial para o desenvolvimento da Síndrome de Burnout, geralmente acompanhada de sintomas físicos e psíquicos.

Sugere-se atentar para os fatores que podem gerar estresse entre os policiais e buscar meios de minimizá-los visando à possibilidade de diminuir o risco de desenvolvimento da Síndrome de Burnout através de intervenções pontuais, tais como as intervenções educativas sobre as estratégias de enfrentamento de estresse, contribuindo para a promoção da saúde desses profissionais. A satisfação com as atividades desenvolvidas no ambiente de trabalho pode contribuir positivamente na saúde do policial e repercutir na qualidade da segurança pública que ele faz.

Neste artigo foram sinalizadas algumas características do trabalho do policial que demandam atenção, sobretudo dos profissionais de Saúde do Trabalhador. É importante esclarecer que este estudo não tem qualquer pretensão de fazer juízo de valor sobre as questões organizacionais e estruturais relacionadas ao trabalho militar, mas sinalizar a necessidade de reflexão sobre o trabalho neste cenário, a fim de minimizar os impactos na saúde dos policiais e consequentemente contribuir com a segurança pública.

\section{REFERÊNCIAS}

1. Rocha SV, de Araújo EM. Implicações do processo de produção na saúde dos trabalhadores: algumas reflexões. Rev. Saúde. Com. [Internet] 2011; 7(1) [acesso em 04 fev 2014]. Disponível: http://www.uesb.br/revista/rsc/v7/ v7n1a08.pdf.

2. Sousa MVH. Síndrome de Burnout em profissionais da saúde: estudo bibliográfico [monografia]. Picos (PI): Universidade Federal do Piauí; 2012.

3. de Souza ER, Minayo MCS, Silva JG, Pires TO. Fatores associados ao sofrimento psíquico de policiais militares da cidade do Rio de Janeiro, Brasil. Cad. Saúde Pública. [Internet] 2012; 28(7) [acesso em 03 fev 2014]. Disponível: http://dx.doi.org/10.1590/S0102-311X2012000700008.

4. Dantas MA, Brito DVC, Rodrigues PB, Maciente TS. Avaliação de estresse em policiais militares. Psicologia: Teoria e Prática. [Internet] 2010; 12(3) [acesso em 03 fev 2014]. Disponível: http://pepsic.bvsalud.org/pdf/ptp/ v12n3/v12n3a06.pdf.

5. Pineles SL, Rasmusson AM, Yehuda R, Lasko NB, Macklin ML, Pitman RK, et al. Predicting emotional responses to potentially traumatic events from pre-exposure waking cortisol levels: a longitudinal study of police and firefighters. Anxiety Stress Coping. [Internet] 2013; 26(3) [acesso em 05 jan 2015]. Disponível: http://dx.doi.org/1 $0.1080 / 10615806.2012 .672976$.

6. Baughman P, Andrew M, Burchfiel C, Fekedulegn D, Violanti J, Miller D. Salivary cortisol response to a highprotein challenge and metabolic syndrome in police officers. Occup Environ Med. [Internet] 2014; 71(Suppl 1) [acesso em 20 jan 2015]. Disponível: http://dx.doi.org/10.1136/oemed-2014-102362.181.

7. Pinto JN, Lautert L, Dick NM. Absenteísmo por doença na brigada militar de Porto Alegre. Rev. HCPA. $32^{\mathrm{a}}$ Semana Científica. [Internet] 2012 [acesso em fev 2015]. Disponível: https://www.lume.ufrgs.br/bitstream/ handle/10183/70767/000871822.pdf? sequence $=1$.

8. Tavares JP. Relação entre as dimensões do modelo desequilíbrio esforço-recompensa, resiliência e níveis de cortisol salivar entre policiais militares [tese]. Porto Alegre (RS): Universidade Federal do Rio Grande do Sul; 2015.

9. Menegali TT, Camargo RPM, Rogerio LPW, de Carvalho DC, Magajewski FRL. Avaliação da Síndrome de Burnout em policiais civis do município de Tubarão (SC). RevBrasMed Trab. [Internet] 2010; 8(2) [acesso 20 nov 2014]. Disponível: http://www.anamt.org.br/site/upload_arquivos/revista_brasileira_volume_8_n\%C2\%B0_2_-dez_2010_1212201310152533424.pdf.

10. Guimarães LAM, Mayer VM, Bueno HPV, Minari MRT, Martins LF. Síndrome de Burnout e qualidade de vida de policiais militares e civis. Revista Sul Americana de Psicologia. [Internet] 2014; 2(1) [acesso em 06 fev 2015]. 
Disponível: http://revista.unisal.br/am/index.php/psico/article/view/32/44.

11. Forte ECN, Trombetta AP, Pires DEP, Gelbcke FL, Lino MM. Abordagens teóricas sobre a saúde do trabalhador de enfermagem: revisão integrativa. CogitareEnferm. [Internet] 2014; 19(3) [acesso em 15 dez 2015]. Disponível: http://dx.doi.org/10.5380/ce.v19i3.35379.

12. Ministério da Saúde (BR). Secretaria Executiva. Núcleo Técnico da Política Nacional de Humanização. Humaniza SUS: Política nacional de humanização: Documento base para gestores e trabalhadores do SUS. Brasília: Ministério da Saúde; 2004.

13. Franco GP, de Barros ALBL, Nogueira-Martins LA, Zeitoun SS. Burnout in nursing residents. Rev. esc. enferm. USP. [Internet] 2011;45(1) [acesso em 04 jan 2015]. Disponível: http://dx.doi.org/10.1590/S0080-62342011000100002.

14. Maslach C, Jackson SE. The measurement of experienced burnout. J. Organ. Behav. [Internet] 1981; 2(2) [acesso em 26 mar 2016]. Disponível: http://dx.doi.org/10.1002/job.4030020205.

15. Oliveira PLM, Bardagi MP. Estresse e comprometimento com a carreira em policiais militares. Bol. psicol. [Internet] 2009; 59(131) [acesso em $12 \mathrm{dez}$ 2015]. Disponível: http://pepsic.bvsalud.org/pdf/bolpsi/v59n131/ v59n131a03.pdf.

16. Gil-Monte PR, Peiró JM. Validez factorial del maslach burnout inventory en una muestra multiocupacional. Psicothema.[Internet] 1999; 11(3) [acesso em 16 abr 2016]. Disponível:http://www.psicothema.com/pdf/319.pdf.

17. Silva LCF, Lima FB, Caixeta RP. Síndrome de burnout em profissionais do corpo de bombeiros. Mudanças, Psicol. Saúde. [Internet] 2010; 18(1-2) [acesso em 02 jan 2016]. Disponível: https://www.metodista.br/revistas/ revistas-ims/index.php/MUD/article/viewFile/2270/2704.

18. Minayo MCS, de Souza ER, Constantino P. Missão prevenir e proteger: condições de vida, trabalho e saúde dos policiais militares do Rio de Janeiro. Rio de Janeiro: Editora Fiocruz; 2008.

19. Pereira AMB. Burnout: quando o trabalho ameaça o bem-estar do trabalhador. São Paulo: Casa do Psicólogo; 2002.

20. Schizzi AMG.Síndrome de Burnout entre os trabalhadores de enfermagem [monografia]. Novo Hamburgo (RS): Centro Universitário Feevale; 2007.

21. Ministério da Saúde (BR). Conselho Nacional de Saúde. Diretrizes e normas regulamentadoras de pesquisa envolvendo seres humanos. Resolução n. 466, de 12 de dezembro de 2012. Brasília; 2012.

22. Vasques-Menezes I. A contribuição da psicologia clínica na compreensão do Burnout: um estudo com professores [tese]. Brasília (DF): Instituto de Psicologia da UnB; 2005.

23. Tamayo MR, Tróccoli BT. Construção e validação fatorial da escala de caracterização do Burnout (ECB). Estud. psicol. [Internet] 2009; 14(3) [acesso em 02 mar 2016]. http://dx.doi.org/10.1590/S1413-294X2009000300005.

24. França SPS, de Martino MMF, Aniceto EVS, Silva LL. Preditores da síndrome de burnout em enfermeiros de serviços de urgência pré-hospitalar. Acta paul. enferm. [Internet] 2012; 25(1) [acesso em 02 dez 2015]. Disponível: http://dx.doi.org/10.1590/S0103-21002012000100012.

25. Magalhães E, Oliveira ÁCMS, Govêia CS, Ladeira LCA, Queiroz DM, Vieira CV. Prevalência de síndrome de burnout entre os anestesiologistas do Distrito Federal. Rev. Bras. Anestesiol. [Internet] 2015; 65(2) [acesso em 02 mar 2016]. Disponível: http://dx.doi.org/10.1016/j.bjane.2013.07.016.

26. Cracco CLAC, Salvador JA. Identificação da síndrome de burnout na equipe de enfermagem de uma unidade de pronto atendimento [monografia]. Lins (SP): Centro Universitário Católico; 2010.

27. Lazarus RS, Folhman S. Stress, appraisal, and coping. New York: Springer, 1984.

28. Rezende AAB, Rodrigues ESR, Herrera SDSC, Silveira JM, Barreto KKS, do Carmo PHF. Prevalência de tabagismo em policias militares. Rev. méd. Minas Gerais. [Internet] 2012; 22(2) [acesso em 15 dez 2015]. Disponível: http:// www.rmmg.org/artigo/detalhes/95. 
29. Minayo MCS, de Assis SG, de Oliveira RVC. Impacto das atividades profissionais na saúde física e mental dos policiais civis e militares do Rio de Janeiro (RJ, Brasil). Ciênc. saúde coletiva. [Internet] 2011; 16(4) [acesso em 12 dez 2015]. Disponível: http://dx.doi.org/10.1590/S1413-81232011000400019.

30. Moreno FN, Gil GP, Haddad MCL, Vannuchi MTO. Estratégias e intervenções no enfrentamento da síndrome de burnout. Rev. enferm. UERJ. [Internet] 2011; 19(1) [acesso em 13 dez 2015]. Disponível: http://www.facenf.uerj. br/v19n1/v19n1a23.pdf. 